\title{
MODELLING AND SIMULATION OF A SOLAR POWER PLANT WITH A DISTRIBUTED COLLECTORS SYSTEM
}

\author{
E. F. Camacho, F. R. Rubio and J. A. Gutierrez
}

Dpto. Ingenieria Electronica, de Sistemas y Automatica, E.T.S. de Ingenieros

Industriales, Ada. Reina Mercedes s/n, 41012-Serilla, Spain

\begin{abstract}
This paper presents a model and computer simulation results of the distributed collectors field of a solar power plant. This plant is located in Tabernas (Almeria - Spain). The dvnamic behaviour of the distributed collectors field is simulated by 100 lumped parameter submodels. Temperatures of the oil and the tube wall geometry, mirrors reflectivity, solar radiation, and the inlet field oil temperature,
\end{abstract}

Keywords. Modelling, Nonlínear sygtem, Solar energy.

\section{INTRODUCTION}

Solar energy is increasingly used nowadays for different purposes. in a wide variety of processes. The main features of solar energy are that although it is a cheap source of power, the devices needed to obtain it are expensive and also its primary source cannot be manipulated. Because of all this an ootimun design of equipment and operating conditions becomes necessary. Computer simulation would appear to be the ideal tool for achieving this objetive.

This article presents a dunamic model of a distributed collector field installed at the solar plat form in Almerla (Spain). The collector loop is the basic subsystem which determines the behaviour of a collector field. If it is possible to model a loop. the behaviour of the whole field can be determined by simply adding the parallel loops and allowing for transport delays in the interconnecting tubes.

The solar plant was designed with three heat transfer loops. One loop extracts cold ofl from the bottom of a thermal storage tank, c1rculates it through the collector fleld and returns it to the top of the tank. The second loop extracts hot oll from the top of the storage tank, circulates it through the vaporizer heat exchange unit and returns it to the bottom of the tank. The third loop circulates toluene through the interchange to vaporize it and then expands the vapor through the turbine in the power conversion module to extract the energy for electrical power generation.

The present model has been developed to fulfill the following objetives:

- The simulation of the field behaviour in order to optinlze the temperature regulation system.

- A study of the behaviour of the systen under specific operational conditions such as the starting phase or clouds passing.

- A study of extreme situations by imulation of punp fallures, desteer mechanisns, etc.

- Its application to other collector fields by modifying the corresponding parameters.
The model allows the temperature distribution in the absorbtion tube and in the thermic oil alongthe collector loop at a given moment. as well as the temporary variation of the temperatures at determined points of the collector.

A description of the plant is given in section 2 of this article. Section 3 describes how the principal parameters of the model have been obtained. Section 4 gives the results of the process simulation and compares them to real values obtained by various tests on the plant. Section 5 describes how a gain scheduling Section 5 describes how a gain scheduling
regulator has been obtained using the model and how this has led to an improvement in the temperature control of the loop. Lastly conclusions are made in section 6 .

\section{A DISTRIBUTED MODEL OF THE COLLECTOR FIELD}

The fleld consists of 480 distributed solar ACUREX collectors. These collectors are arranged in 20 rows which form 10 parallel loops as shown in Fis. 1 .

The collector uses a parabolic surface to concentrate the direct normal beam onto the receiver tube, which is located at the focal point of the parabola. The heat transfer fluid is pumped of the parabola. The heat transfer fluid is pumped
through the receiver tube and picks up the heat transfered through the receiver tube walls.

The field is also provided with a sun trackins system which causes the mirrors to revolve around an axis parallel to that of the pipe. The seeking mechanlsm can reach three possible states:

Track: The mechanism seeks the sun and collectors focus on the pipe.

Desteer: The mechantan steers collector several degrees away from the sun and continues tracking with the receiver out of focus. This protects the field in case of a pump fallure from over-heating.

Stow: The mechanism moves collector to an inverted position at the end of each day or if serious alarm happens. 


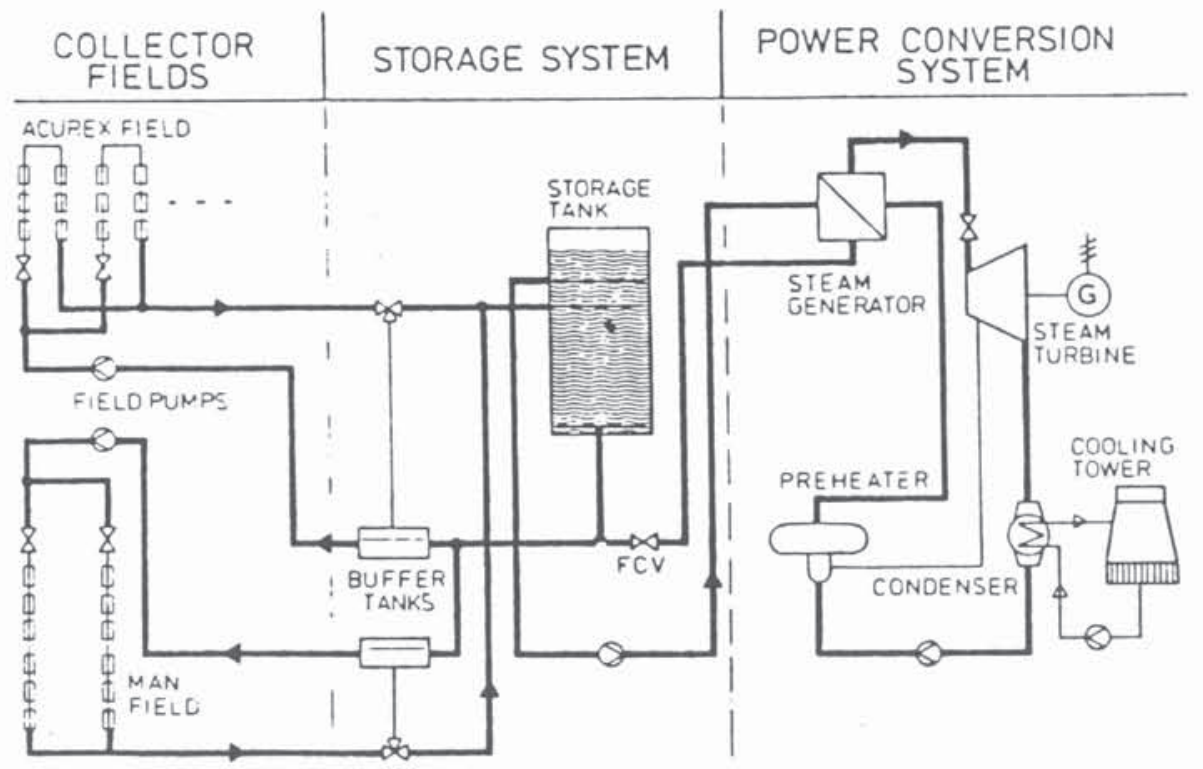

FIG. I Simplifled DCS Process Flow Diagram

The system takes about 5 minutes to take the field from the stow to the track position and only about 20 seconds to go from the desteer to the track position.

The cold inlet oil is extracted from the bottom of the storage tank and is passed through the field using a pump located in the field inlet. This fluid is heated and then introduced into a storage tank to be used for electrical energy generation. The system is provided with a three way valve located in the field outlet that allows the oil to be recycled in the field until its outlet temperature is adequate for entering into the top of the storage tank. A more detailed field description can be found in (Kalt, 1982).

Each of the loops mentioned above is formed by four twelve module collectors, suitably connected in series. The loop is 172 metres long, the active part of the loop measuring 142 metres and the passive part 30 metres. Due to the complexity of the system and the existence of nonlinearities a numerical model has been evolved to simulate it, the following hypotheses having been made:

- The properties of the oll are considered as functions of the temperature.

- The flow in each section is presumed to be circumferentially uniform and equal to the average value.

- Variations in the radial temperature of the tube walling are not taken into account. Th1s assumption is reasonable in the case of a thin wall with good thermal conductivity.

- The 011 flow and the irradiance are considered as time functions and are always the same for each element (an uncompressable fluid is presumed).

- Losses caused by the conduction of axial heat on both sides of the wall and from the fluid are negligible. The axial conduction in the tube should be slight given that the walling is thin, having a high heat resistance. The axial conduction in the fluid is relatively slight the ofl conductivity is poor.

Using the above hypotheses and applying the conservation of the enersy in the metal tube of a length control volume $d x$ over a time interval $d t$. one has that:

$$
\begin{aligned}
P_{m} C_{m} A_{m} \frac{\partial T_{m}}{\partial t}=I n_{0} D-H_{1} G\left(T_{m}\right. & \left.-T_{a}\right) \\
& -L H_{t}\left(T_{m}-T_{f}\right)
\end{aligned}
$$

Similarlv for a fluid element:

$P_{f} C_{f} A_{f} \frac{\partial T_{f}}{\partial t}+P_{f} C_{f} \dot{V} \frac{\partial T_{f}}{\partial x}=L H_{t}\left(T_{m}-T_{f}\right)$

In the above equations the subindex mefers to the metal and that of $f$ to the fluid and:

$P=0 i l$ density

$C=$ field capacity

$A=$ transversal area

$\mathrm{T}=$ outlet temperature

$I=i r r a d i a n c e$

$n_{0}=$ optical efficiency

$H_{1}^{\circ}=$ overall thermal loss coefficient

$D^{1}=$ mirrors $^{\circ}$ width

$H_{t}=$ coefficlent of metal fluid transmission

$G^{t}=$ exterior diameter of the pipe line

$L=$ inner diameter of the pipe line

$V=011$ flow rate

The equations which describe the performance in a passive element are similar except that solar energy entrance is nil and the heat loss coefficlent is much less.

These equations have been solved using an iterative process with finite differences. The temperatures of the fluid and of the absorbency tube are calculated for each time interval and for each element. Each segment is ! metre long and the integration interval is $0.5 \mathrm{sg}$.

A two stage alsorithm has been chosen to solve the temperature equations. In the first stage the temperatures of the fluid and of the metal are calculated supposing that the fluid is in a steady state. In the second stage the fluid temperature is corrected in function of the net energy transported by the fluid. 


$$
\begin{aligned}
& 1^{\text {st }} \text { Stage } \\
& T_{m}(n, k)=T_{m}(n, k-1)+\frac{\Delta t}{R \Phi_{m} C_{m} A_{m}}\left(I n_{0} D-H_{1} G\right. \\
& \left(T_{m}(n, k-1)-T_{a}\right)-L H_{t} l\left(T_{m}(n, k-1)-T_{1 f}(n, k-1)\right) \\
& T_{f}(n, k)=T_{1 f}(n, k-1)+\frac{H_{t} 1 \Delta t}{R \Phi_{f} C_{f} A_{f}}\left(T_{m}(n, k-1)\right. \\
& \left.2^{n d} \text { Stage }-T_{1 f}(n, k-1)\right) \frac{\dot{V} \Delta t}{T_{1 f}(n, k)=} T_{f}(n, k-1)-\cdots x \\
& \left.\quad-T_{f}(n-1, k)\right) \quad T_{f}(n, k)
\end{aligned}
$$

In these difference equations $T^{T}(n, k)$ and $T_{m}(n, k)$ afe the temperatures in the $n{ }^{\text {th }}$ segment during the $k$ time interval. T is the fluid temperature before correction and $\mathrm{T}_{\mathrm{f}}$ is the fluid temperatura after correction.

\section{MODEL PARAMETER ADJUSTHENTS}

The different constants and coefficients used in the previous equations have been determined using real data from the plant. many of them being adjusted to polinomial functions of the temperature, by a minimal squares method.

\section{Properties of Theraal Fluid}

The fluld used to transport the thermal energy is Santotherm 55, a thermal oll which allows working temperatures above $300^{\circ} \mathrm{C}$ without decomposing. One of the main characteristics of this oil is its low thermal conductivity. Furthermore its density is highly dependent on 1 ts temperature, which permits the use of Just one storage tank to contain both the hot and the cold oil in thermal stratification (the thermocline effect). The tank used in this collector fleld has a capacity of $140 \mathrm{~m}^{3}$ which allows the storage of 2.3 thermic Mwh for an inlet temperature of $210^{\circ} \mathrm{C}$ and an outlet one of $290^{\circ} \mathrm{C}$. The good thermal stratiflcation of this oil allows it to be stored for various days as has been shown by (Andersson, 1983).

From data supplied by the oll producer (Kalt, 1982), Its physical properties have been obtained as the following polynomial function of the temperature.

a) Density $P=903-0.672 \mathrm{~T} \mathrm{Kg} / \mathrm{m}^{3}$.

b) Specific thermal capacitv $\mathrm{Cf}=1820+3.478 \mathrm{~T}$

c) Thermal conductivity $\mathrm{Kf}=0.1923-1.310^{-4} \mathrm{~T}$ $\omega / m{ }^{\circ} \mathrm{C}$

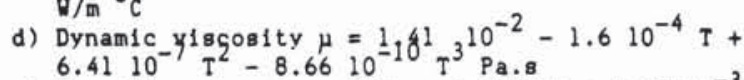

e) $\mathrm{P}_{5}$ andit number $\mathrm{B}_{3}=212-2.2786 \mathrm{~T}+8.9710^{-3}$

\section{Therael Transference Coefficlent}

This coefficient can be expressed as a function of two variables: the flow and a coefficient depending on the temperature.

$$
H t=H v(T) \dot{v}^{0.8}
$$

Hv( $T$ ) has been evaluated for different temperatures and by adjusting the values obtained to a polynomial one gets that:

$$
\begin{aligned}
\mathrm{Hv}(\mathrm{T})= & 2.1710^{6}-5.0110^{4} \mathrm{~T}^{-4} 4.5310^{2} \mathrm{~T}^{2} \\
& -1.64 \mathrm{~T}^{3}+2.110^{-3^{4}} \mathrm{~T}^{4} .
\end{aligned}
$$

\section{Global Coefficient of Thermal Losses}

The losses have been evaluated by various tests carried out on the ACUREX field. with the oll circulating and the collector in the stow position. In the steady state the losses are calculated by multiplying the enthalpy lost in the oil by the masic flow.

Using the data, it has been established that the total amount of the losses can be approximated by

$$
\text { Lt }=0.00667 \mathrm{DTm}^{2}-0.164 \mathrm{DTm}
$$

where DTm is the difference in temperature between the average inlet and outlet temperature and the atmosphere temperature. The loss coefficient is given by:

$$
\begin{aligned}
& \mathrm{H} 1=\mathrm{Lt} / \mathrm{A} \text { DTm : with A }=2674 \mathrm{~m} \\
& \text { that is, HI }=0.00249 \mathrm{DTm}-0.06133
\end{aligned}
$$

In the model the thermal loss coefficient is calculated by applving the above equation to each element of length and having DTm equal to the temperature of this element minus the ambient temperature.

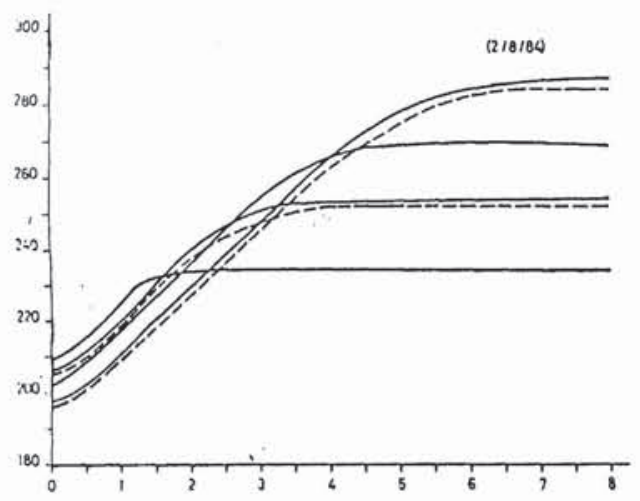

FIG. 2 Collector behaviour when changed from stow to track position

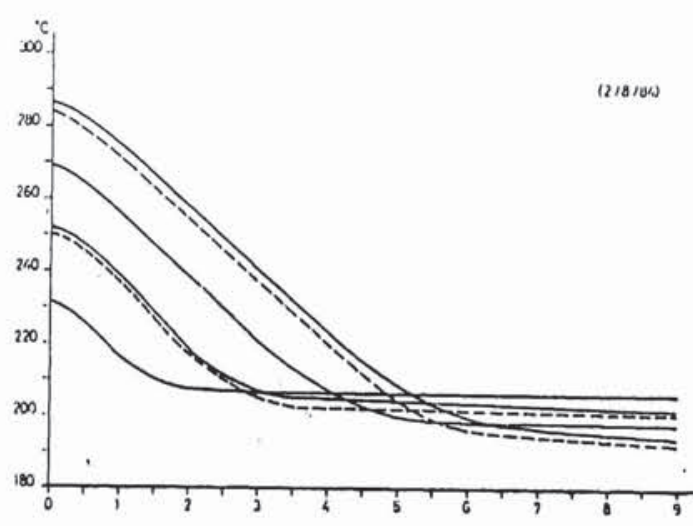

FIG. 3 Collector behaviour when changed from track to desteer position 


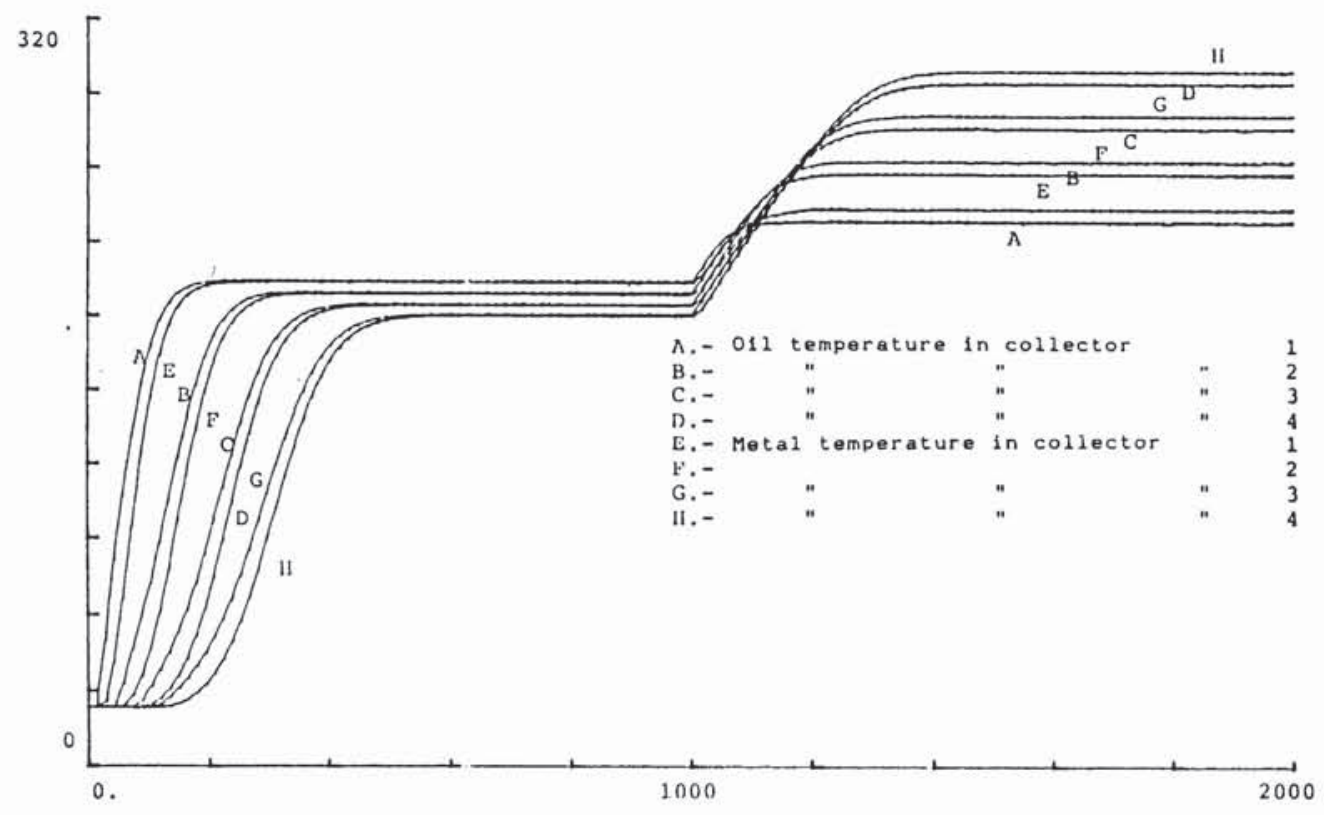

FIG. 4 Response to a step change in the outlet temperature and in the Irradiance

\section{Deternination of the effective Surface}

The amount of shadows produced bv each mirror on the others and therefore the effective surface of the collector field depends on the position of the sun. To take into account these effects the position of the sun is first calculated based on the solar hour. Julian day, the vear and the local latitude. From this we obtain:

$$
\delta 1=23.45 \sin (360(284+J D) / 365)
$$

The incidence angle (the angle between the solar vector and the normal vector to the surface of the collector) is given by:

$$
\begin{aligned}
& \cos \$=\left(1-\cos ^{2} \delta 1 \sin ^{2} \delta 2\right)^{1 / 2} \\
& \text { with }: \$ 2=15 \text {. }\left(T_{8}-12\right) \\
& \$ 2=\text { hourlv angle } \\
& \mathrm{Ts}=\text { solar hour }
\end{aligned}
$$

The effective surface being:

\section{$S=$ Sref Eo}

EO $=1-($ NRS S1 SW+2 NCWH $W \$) /($ NRT MN DM W)

Where Eo 18 the global optical efficiency and Sref $=264.4 \mathrm{~m}^{2} 18$ the reflecting surface of the mirrors of the ACUREX field under consideration, The other factors are the dimensions of the collector.

\section{VALIDATION OF THE MODEL}

Varlous tests have been carricd out to compare the results of the model gimulation with the experimental data. Fig. 2 shows the outlet temperature of each collector and that of the total outlet of the loop. When the loop 1s taken from stow to track the sun. The inlet temperature is $215{ }^{\circ} \mathrm{C}$. the irradiance $902 \mathrm{~m} / \mathrm{m}^{2}$ are reflectivitv 0.81 , and the flow $1 \mathrm{~s}$ maintained at $0.641 / 8 g$.

The curves of the continuous line correspond to the model outputs and those of the broken one to real values of the plant. The maximum difference in the outlet temperature of the loop is about 3 ${ }_{C} \mathrm{C}$ between the model and the plant, representing about $1 \%$ of the real value, which can be considered to be acceptable.

In the same way Fig. 3 represents the outlet temperature of each collector when the field is in the desteer position.

Fig. 4 shows the results of the simulation of the four collectors modules of a lcop when stimulated by a step in the inlet temperature and afterwards by a step in irradiance. The temperatures of the metal are started at ambient temperature of $25^{\circ} \mathrm{C}$. When $t=0$ the inlet temperature becomes equal to $212{ }^{\circ} \mathrm{C}$ which 18 the normal working temperature. When $t=180088$. . the irradiance changes from 0 to $900 \mathrm{w} / \mathrm{m}^{2}$. to simulate the change between the stow and track states.

Fig. 5 shows the behaviour of the collector field when faced with a change in the flow. The real and simulated data are represented. The operational conditions are:

- Inlet temperature: $215{ }^{\circ} \mathrm{C}$ - Hour ( $801 \mathrm{ar}$ ): 11:50 - Irradiance: $890 \mathrm{w} / \mathrm{m}^{2}$ - Flow: $71 / 8 g$.

- Reflectivity: $0.83 \quad$ - Outlet temp: $277{ }^{\circ} \mathrm{C}$
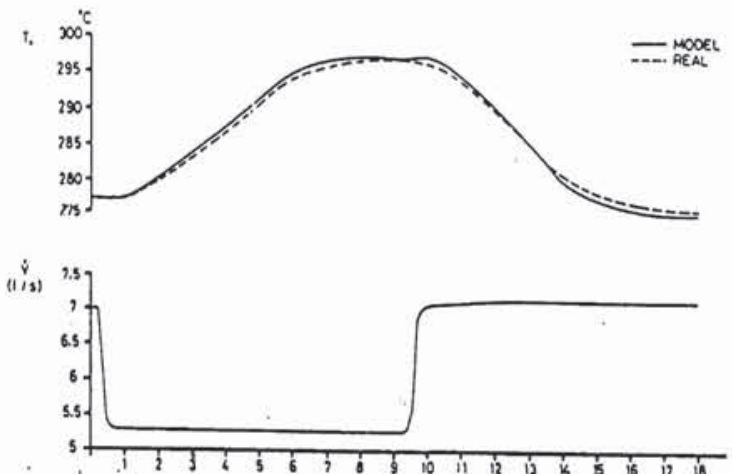

FIG. 5 Outlet temperature. a) Real data. b) Simulated data. 
Under these conditions the flow is changed between 7 and $5.3 \mathrm{1} / \mathrm{sg}$, and afterwards the flow is again increased to 7 1/sg. staving constant until the end of the test. The error between both results is less than $1{ }^{\circ} \mathrm{C}$ during the test.

\section{GAIN SCHEDULING REGULATOR}

The model described above has been used to calculate a P.I. regulator. at different operating conditions of the plant.

The difference equation which represent this regulator is:

$$
u(k)=u(k-1)+q 0 e(k)+q 1 e(k-1)
$$

The parameters qo and $q 1$ should be adapted to the process dynamic in order to obtain good controllability. When the backward approximation of the analogical PI is used. the relationships obtained between these coefficients $(q 0, q 1)$, the gain $(K)$ and the integral time (Ti) are:

$$
K=-q l: \quad T i=-T m q l /(q l+q 0)
$$

To obtain the regulator parameters the Powel ootimization method (Powel1. 1964) has been used, minimizing the criterium:

$$
\sum_{i-1}^{N} e_{i}^{2}+K p \operatorname{Smax}
$$

Where Smax is the overshoot obtained for each set of parameters.

Using this criterium the parameters of the regulator at various working points have been obtained. From these data it can be observed that they can be expressed as a function of the flow at any given moment. Adjusting a polynomial expression to the obtained points one has that:

$$
\begin{aligned}
& K=0.0205-0.0375 \dot{v}+0.0023 \dot{v}^{2} \\
& T_{1}=465-46.6 \dot{v}
\end{aligned}
$$

In figures 6 and 7 a fixed regulator calculated for a medium working Doint is compared to the gain scheduling regulator previously calculated. In these tests the system has been subjeted to reference steps of between 280 and $290{ }^{\circ} \mathrm{C}$ in an reference steps of between 280 and $290 \mathrm{C}$ in an seen to behave in a more acceptable way than the fixed regulator. which only works satisfactorily about the operational point for which it was calculated.

\section{CONCLUSIONS}

A model of distributed parameters which describes the behaviour of a collector loop installed in the solar plant of Almeria (Spain) is presented. This model can represent other fields just by variying the parameters. The model was validated by comparing the results obtained by simulation with real data. It has also been used to design a gain scheduling regulator, which has ooked to be more effecient than a fixed regulator.

\section{ACKNOULEDGKENT}

The authors would like to acknowledge the help of the CAICYT and the Junta de Andalucia that supported this work under srant number $1102 / 84$ and number 07/CLM/MDM respectively.

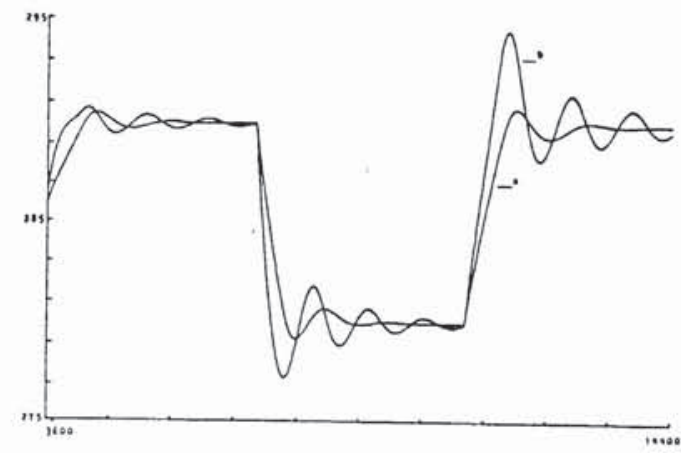

FIG. 6 Outlet temperature with a high flow. a) Gain scheduling regulator.

b) Fixed regulator

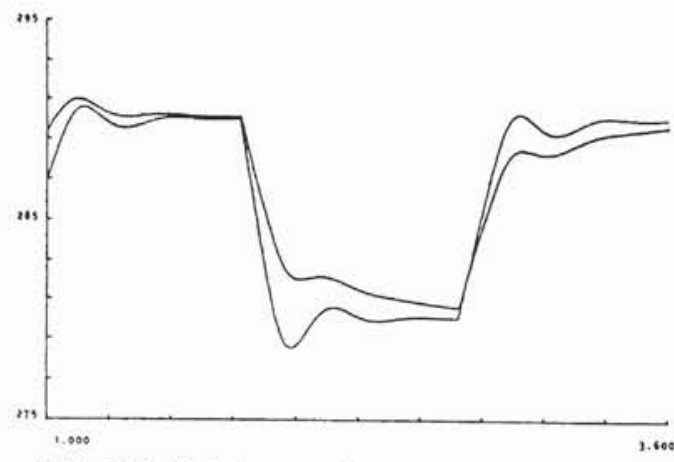

FIG. 7 Outlet temperature with a low flow.

a) Gain scheduling regulator.

b) Fixed regulator

\section{REFERENCES}

Carmona, R. (1985). Análisis, Modelado y Control de un Campo de Colectores Solares Distribuidos con Sistema de Seguimiento en un ele. Doctoral thesis. Univ. Sevilla.

Carmona, R. (1984), Estimate of 011 Flowrate in the Acurex Field. IEA/SSPS Internal Report, $\mathrm{R}-43 / 84 \mathrm{RC}$.

Gutierrez, J.A.. F.R. Rubio. E.F. Camacho y R. Carmona (1986). Fully Automation of a Distributed Collectors Field of a Solar Power Plant. Preprints of the Symposium International IFAC on Components, Instruments and Techniques for Low Cost Automation and Applications. (LCA 86), pp 381-386, Valencia (España).

Kalt, A, et al, (1982), Distributed Collector System Plant Construction Report. IEA/SSPS Operating Agent DFVLR. Cologne, FRG.

Powell, D.M. (1964), An Efficient Method for Finding the Minimun of a Function of Several VAriables without Calculating Derivatives. Computer Journal. 7 pp. 155.

Rubio, F.R. (1985), Control Adaptativo de Procesos Industriales. Aplicacion a una Central Solar. Doctoral thesis ETSII. Sevilla.

Sánchez, M. and Delgado, A. (1985), Geometrical Factors for Parabolic Collectors which Track the Sun around an East-West Axis: Applied to the ACUREX Field. IEA/SSPS Internal Report R-34/85MSAD. 